\title{
A NARRATIVA DO PERPETRADOR NO BRASIL: MEMÓRIAS QUASE PÓSTUMAS DE UM EX-TORTURADOR E MEMÓRIAS DE UMA GUERRA SUJA
}

\author{
Tânia Sarmento-Pantoja ${ }^{1}$
}

\begin{abstract}
RESUMO: A categoria "narrativa do perpetrador" é aqui proposta com base no paralelo com a categoria "romance do ditador" ou "narrativa do ditador". Desse modo, da mesma forma que o romance do ditador tematiza e confere protagonismo ao tirano, a exemplo do paradigmático El otoño del patriarca e o recente $L a$ fiesta del chivo, sugerimos a narrativa do perpetrador como aquela que tematiza e confere protagonismo ao perpetrador, considerando o perpetrador como aquele que comete ato condenável, crime ou delito. No caso das narrativas analisadas neste estudo consideramos o perpetrador como todo agente fiscalizador e punitivo pertencente ao braço armado dos regimes de exceção. Sendo uma extensão do tirano o perpetrador é o responsável direto pelo funcionamento da máquina repressiva: ora o policial que investiga e colhe informações sobre os opositores do regime, ora a autoridade responsável por planejar e conduzir as ações repressivas, ora o torturador que executa as sevícias, os desaparecimentos e os assassinatos. Como forma de compreender o funcionamento da narrativa do perpetrador, apresentamos a análise do romance Memórias quase póstumas de um ex-torturador (2006), de João Bosco Maia, e o testemunho mediado Memórias de uma guerra suja (2012), de Rogério Medeiros e Marcelo Netto, com base nos depoimentos do ex-delegado do DOPS Cláudio Guerra.

Palavras-Chave: Resistência. Narrativa. Perpetrador. Ditadura.
\end{abstract}

\begin{abstract}
The category "perpetrator narrative" is proposed here based on the parallel with the category "novel of dictator" or "narrative of dictator". Thus, in the same way that the novel of the dictator thematizes and gives protagonism to the tyrant, like the paradigmatic El otoño del patriarca and the recent La fiesta del chivo, we suggest the perpetrator narrative as the one that thematizes and gives protagonism to the perpetrator, considering the perpetrator as one who commits a reprehensible act, crime or offense. In the case of the narratives analyzed in this study, we consider the perpetrator as any fiscalizing and punitive agent belonging to the armed wing of the exception regimes. Being an extension of the tyrant, the perpetrator is directly responsible for the operation of the repressive machine: sometimes the police officer who investigates and gathers information about opponents of the regime, sometimes the authority responsible for planning and conducting repressive actions, or the torturer who executes the, disappearances and murders. As a way of understanding the functioning of the perpetrator narrative, we present the analysis of the novel Memórias quase póstumas de um ex-torturador (2006), by João Bosco Maia, and the mediaded testimony Memórias de uma guerra suja (2012) by Rogério Medeiros and Marcelo Netto, based on the testimony of former DOPS delegate Cláudio Guerra.
\end{abstract}

Keywords: Resistance. Narrative. Perpetrator. Dictatorship.

\section{A narrativa do ditador}

Em Geografia de La Novela (1993) Carlos Fuentes nos revela que ele e Mario Vargas Llosa após lerem Patriotic Gore (1962), de Edmund Wilson, livro sobre personagens da guerra de Guerra de Secessão norte-americana, avaliaram ser possível produzir algo semelhante, que tivesse como cenário a América Latina e como protagonistas os ditadores latino-americanos. Apesar da ideia nunca ter de fato se materializado como pretendiam inicialmente, acabou rendendo produções paradigmáticas para o cânone daquilo que ficaria conhecido como o romance do ditador: Yo, el supremo (1974), de Roa

\footnotetext{
1 Professora Associada II da Universidade Federal do Pará atuando na Graduação e na Pós-Graduação. E-mail: t.sarmentopantoja@gmail.com.
} 
Bastos El otoño del patriarca (1975), de Gabriel Garcia Márquez, e El recurso del método (1974), de Alejo Carpentier. Todos com o protagonismo do ditador.

De acordo com Márcia Hoppe Navarro (1989, p. 14) ao apresentarem "o ditador como protagonista da narrativa, favorecendo um escrutínio detalhado, não apenas de sua ação política, mas também de sua personalidade", dessa maneira o humanizando, esses três escritores podem ser considerados inovadores em relação à produção precedente e criadores de uma vertente específica do romance desenvolvido na América Latina. No entanto a literatura voltada para a figura do déspota é muito anterior a publicação desses três romances. Para Adriana Fiúza, baseada em Carlos Pacheco, desde o século XIX escritores publicam narrativas que ao mesmo tempo tematizam e denunciam a tirania, como é o caso dos romances Tirano Banderas (1926), de Ramón María del Valle-Inclán que ironicamente, como bem evidencia Fiúza (2008, p.280), é pertencente à literatura espanhola, e El señor presidente, de Miguel Angel Asturias (1946). Um dos romances do ditador mais recentes é La fiesta del chivo (2000), de Mario Vargas Llosa. Vale ressaltar que a violência emanada das ações do ditador funciona como co-protagonista nesses romances, desdobrando-se em soluções narrativas que aprofundam a complexidade disposta na figura daquele que centraliza o poder soberano. Violência fundamentalmente voltada à repressão, seja na forma alegórica, seja na forma realista.

Desse modo, formou-se um corpus de romances em que facilmente são identificadas as características mais fundamentais da narrativa do ditador, dentre as quais se destaca especialmente o protagonismo dessa figura nuclear. É notável, portanto, o que acontece com narrativas, como a do romance Memórias quase Póstumas de um Ex-torturador (2006), de João Bosco Maia, e a do testemunho romanceado Memórias de uma guerra suja (2012), de Rogério Medeiros e Marcelo Netto, com base nos depoimentos do ex-delegado do DOPS Cláudio Guerra. Nessas duas narrativas o protagonismo é do perpetrador, aqui entendido como todo agente fiscalizador e punitivo pertencente ao braço armado, mais particularmente dos regimes ou condições de exceção.

Em uma categorização ampla a narrativa do perpetrador pode ser categorizada como aquela em que um agente - seja um personagem ou outras formas de agenciamento - em proveito próprio ou daquilo que representa decide pela exclusão física ou simbólica da alteridade e/ou executa essa decisão valendo-se de diversos instrumentos e estratégias. Nesse sentido, o perpetrador pode ser tanto aquele que abstrai e planeja a exclusão, resguardado por alguma autoridade, quanto aquele que pode desenvolver várias funções - profissionais, sociais, institucionais - a fim de concretizar a exclusão. A performance do perpetrador independe da singularidade. Não há diferença, portanto, entre aquele que legisla sobre quem deve calar e aquele que diz: "cale-se!", entre aquele que manda torturar e aquele que tortura, entre aquele que manda matar e aquele que mata. Todos são perpetradores.

O perpetrador é, na extensão do estado de exceção, o instrumento com poderes para violar e imolar o inimigo do estado. Como peças-chaves da máquina repressiva em que o inimigo do estado é o alvo direto e imediato o ditador é tão perpetrador quanto todos os outros envolvidos na engrenagem da repressão, nesse sentido, cada agressor ao responder por suas ordens pode ser visto como um rosto do déspota, e dessa forma repete com outra linguagem e em diferentes cenários o poder soberano imanente ao ditador.

Sendo o déspota ou uma extensão do déspota, o perpetrador é o responsável direto pelo funcionamento, elasticidade e mobilidade dessa máquina repressiva. Nos regimes de exceção ora é o policial que investiga e colhe informações sobre os opositores do regime, ora é a autoridade responsável por planejar e conduzir as ações repressivas, ora é o torturador que executa as sevícias, os desaparecimentos e os assassinatos.

As narrativas citadas não fundam essa possibilidade narrativa. Antes delas podemos citar a título de exemplo os contos "Pedro Ramiro" (1977), de Leandro Konder; "Não passarás o Jordão" (1983), de Luís Fernando Emediato e "A mancha" de Luís Fernando Veríssimo (2003). Nesses contos e da mesma forma no romance de Maia, a agressão física e psicológica, à maneira de suplícios sob os auspícios do perpetrador é uma característica que se destaca. Outros aspectos a salientar são o 
protagonismo do perpetrador, a linguagem abjeta e a vítima, ou melhor, o corpo da vítima: a contraparte do perpetrador, na medida em que constituído por um corpo sofredor e objetifcado é capaz de antagonizar com o corpo do violador. A propósito cito:

"Neste contexto, a definição de corpo ganha um novo aspecto; um novo nome: o de vítima. Pois o corpo sob tortura não é um corpo qualquer, mas aquele que foi objetificado por meio de um processo violento; impetrado por um indivíduo, seu igual enquanto forma (corpo), porém superior em relação ao poder. O corpo-vítima tornase, nas mãos de seu agressor, destituído de seus traços humanos" (BATISTA; SARMENTO-PANTOJA, 2014, p. 03).

Essa redução da humanidade, nos textos literários apontados, se verifica especialmente pela forma como a linguagem é manuseada: vinculada à cena da tortura a linguagem é imersa na abjeção do Outro.

Com base nessas observações este estudo pretende verificar se essa característica em particular se estende ao testemunho mediado de Medeiros \& Netto e se o conjunto favorece a possibilidade de pensar a narrativa do perpetrador como um estrato formal singular ou como uma narrativa derivante da narrativa do ditador, no conjunto de narrativas voltadas à tematizar e problematizar o estado de exceção.

Memórias quase Póstumas de um Ex-torturador" e Memórias de uma guerra suja: narrativas do perpetrador

Em "Memórias quase Póstumas de um Ex-torturador" temos como protagonista um homem bastante idoso que logo após ser diagnosticado com um câncer terminal, sabedor de que lhe restam apenas dois meses de vida e tendo sido o autor de vários assassinatos e agido como torturador durante a ditadura civil-militar de 1964, decide narrar sua história. Fazendo justiça ao título o romance e à clara inspiração machadiana, João Bosco Maia compõe sua narrativa no formato das memórias de um extorturador, Pedro, a partir da perspectiva do próprio torturador. Aos poucos o leitor passa a conhecer a história desse homem cuja infância esteve marcada pela violência paterna.

"Ele nunca me perdoou pela tragédia do embargo, mesmo que por ali já tivessem passado com trauma os outros cinco irmãos. Quando comecei a ganhar peso e saí da condição de quadrúpede, sem que nem para quê, talvez com saudade da racha que eu lhe havia subtraído, largava-me a mão sem dó nem piedade. A princípio o castigo era dado com a mão de remo, mais tarde aliou-se a corda de juta. [...] Junto a isso para patentear a minha culpa, resolveu me chamar pelo nome de Mata Mãe”. (MAIA, 2006, p. 23 e 24$)$

A violência paterna estende seus tentáculos contra outros da família, maculada por esse pai, primeira figura autoritária a deixar seus rastros em corpos alheios, que se confirma perante Pedro por uma revelação hedionda: o pai engravidou a própria filha, a irmã mais velha de Pedro, Ermelinda, com quem teve vários filhos/netos. Mas, apesar de reconhecer a face hedionda desse pai Pedro jamais transcendeu as figurações da violência dele emanadas. Pelo contrário, torna-se um desdobramento dele. Como torturador da ditadura agride violentamente as vítimas para delas "extrair" informações. Os procedimentos de tortura que utiliza contra os corpos violentados são por ele narrados detalhadamente.

"[...] a banheira com água num canto, do outro o armário com a palmatória, "a linha do equador", a "cecê", a "Maria Bonita" e toda sorte de instrumentos para fazer o 
interrogado cuspir a verdade para fora. Do alto do teto, perto de onde estava pendurado o pau-de-arara, desciam os dois cabos elétricos que, quase estavam ligados, transmitiam à carne do inquirido a potência de 110 volts cada um" (MAIA, 2006, p.129)

Nesse processo, vale salientar a presença da linguagem abjeta que no escrutínio do baixo corporal e do baixo calão torna-se reveladora do sofrimento a que são submetidas as vítimas com seus corpos fraturados e, sobretudo, da animalização da figura do perpetrador que, no romance de Maia, é auto-infringida. Essa linguagem é fundamentalmente construída com base em um léxico calcado na versão vulgar dos termos e, portanto, impera o baixo calão, tanto para depreciar, quanto para estabelecer relações com o baixo corporal. Essa linguagem abjeta é muito relevante nos contos citados e em outros da mesma vertente e certamente também é uma marca importante no romance ora analisado.

Essa linguagem, porém, é marcante em certas esferas da experiência que guardam proximidades com a experiência do perpetrador, como mostram alguns estudos fortemente comprometidos com a historiografia das guerras no século XX. Na opinião de Stéphane HudoinRouzeau (2008, p. 392) a transformação dos campos de guerra em verdadeiros matadouros no decorrer do século XX alteraram potencialmente a relação entre o soldado e a experiência corporal da imersão em conflitos intensos, pois não há absolutamente glória naquilo que ele faz, muito ao contrário. Essa alteração repercutiu na linguagem. Baseando-se em um estudo de Paul Fusell, estudioso da língua dos soldados, diz Hudoin-Rouzeau (2008, p. 392):

"Desde a Primeira Guerra Mundial a "linguagem vulgar" dos soldados anglo-saxões quer ser sistematicamente depreciativa para com seu próprio corpo bem como pelo corpo dos outros. A obscenidade e a escatologia são evidentes, contaminando tudo o que há no campo e aparentemente sem propósito a totalidade da linguagem. As palavras shit e fucking, em particular, tendem a se combinar com todas as palavras do vocabulário e todas as abreviaturas usadas na vida militar".

Essa pulsão de aviltamento presente na linguagem, segundo Fussel, é comum na condição militar ou, de quem se encontra imerso em condição semelhante, como é o caso dos perpetradores das ditaduras. Para além dessa hipótese acompanho o raciocínio de Hudoin-Rouzeau (2008, p. 394) para quem o excesso (outrora positivo) de virilidade e brutalidade que sempre acompanhou o modelo clássico do guerreiro ocidental seria uma das chaves para o entendimento dessa linguagem abjeta. Para ela:

"o modelo viril moderno procedente da leitura de extrema direita da experiência de combate da Primeira Guerra Mundial, e mais tarde radicalizada no decorrer da Segunda, não sobreviveu à derrota do Eixo. Isto não significa que não tenha continuado a sobreviver em outras formas, isso até o dia de hoje" (HUDOINROUZEAU, 2008, p. 394).

Junta-se a essa possibilidade a condição de um Estado falido na garantia dos direitos fundamentais do homem ou porque se encontra ausente ou porque o próprio Estado funda e mantém o "monopólio da violência legítima", conforme observa Eric Hobsbawm (2013, p. 348), e mais particularmente nos regimes de exceção por ser o responsável em vários níveis pelo maquinário da tortura e da morte, em cuja saliente engrenagem a figura do perpetrador representa a sua mais perversa ferramenta: ele é a mente e o corpo que sendo um tentáculo do estado de exceção é responsável por investigar, perseguir, capturar, despojar, encarcerar, torturar, eliminar e desaparecer com os corpos de 
opositores. Nesse processo, o corpo do perpetrador funciona como extensão jurídica e executiva do Estado ou do arbítrio de quem decide o estado de exceção.

Desse modo, além de estar assegurado no interior de um aparelhamento logístico e jurídico que se não é militar é francamente inspirado em hierarquias e táticas militarizadas, o perpetrador encontrase livre para expressar o empoderamento à custa do Estado, que lhe garante impunidade, além da indiferença e soberba por saber-se intocável, de modo que não há nenhum mecanismo de contenção capaz de frear seus atos.

O léxico depreciativo indica a representação autoritária que o perpetrador dirige ao seu adversário, aqui na condição do Outro, de forma que a linguagem do perpetrador é despótica não somente por ser depreciativa, mas, sobretudo, por tomar o Outro como objeto a ser dominado e destruído. Sua língua, na representação própria da literatura, é o espelho dessa condição. Nesse percurso, o Outro é reduzido a uma definição negativa extrema: o Outro simplesmente não é. No romance de João Bosco Maia esse aspecto associa-se ao protagonismo: o perpetrador está com a palavra e essa palavra espelha o poder que o guarnece como perpetrador tal como evidente neste trecho: "Quando fez menção de abrir a boca, antecipei-me para mostrar que eu estava com as rédeas do espetáculo" (MAIA, 2006, p. 37).

O desafio da escrita nesse romance é falar sobre a condição aguda do ser violento ao limite do inumano. Vale ressaltar que Pedro se vê como um animal - e sua fala assim o deprecia - e do mesmo modo vê também as suas vítimas, compostas como aptas à sangria e ao abatedouro como no excerto a seguir:

Ao primeiro instrumento, o comunista ordinário se manteve fiel de não falar qualquer coisa sobre seu partido nem entregar aqueles que eles lá chamavam de "camaradas". Grunhiu daqui e dacolá, bufou, deu cambalhotas nos olhos, e se manteve em silêncio renitente, mesmo quando a ponta de gancho do arame lhe foi arrancado do fundo do ureter. [...] não resistiu no instante em que as conchas da "cecê" se fecharam em seus colhões e os foram comprimindo sem qualquer manifestação de pressa (MAIA, 2006, p. 120).

Fugitivo da casa e das sevícias paternas de onde escapole ainda menino o perpetrador do romance de Maia é acolhido por um português, mas termina de ser criado - em duplo sentido - por um alemão chamado Fritz, que o chama somente de "filho da puta". Fritz consegue para o então garoto uma certidão de nascimento falsa, em que o nome destinado a ele é uma dupla alegoria, irônica, do destino que terá: Pedro Álvares Cabral, de nacionalidade portuguesa. Fritz, na verdade, é agente disfarçado do DOPS (Departamento de Ordem Política e Social) e acaba por levar Pedro a se tornar mais tarde torturador profissional no quadro da repressão da ditadura civil-militar brasileira.

Espelho do pai, em "Memórias quase Póstumas de um Ex-torturador", Pedro repete também em casa a conduta violenta de que tentou escapulir: é o marido abusador que em nome de um ciúme doentio persegue e aterroriza sua esposa, acusando-a do "hábito de trepar com o primeiro que aparecesse" como uma "égua no cio" (MAIA, 2006, p. 17), expondo-a a situações vexatórias, reclusão e agressões:

Quantas vezes eu não varei a noite, atrás daquela porta, com aquele gatilho a ponto de disparar na esperança de encontrar um peito no escuro que gritasse de dor e levantasse para o alto o braço vitorioso da minha vingança! Mas eles não vinham em matéria nem sob qualquer forma. Passavam invisíveis através da minha tocaia, sem que eu pudesse mirar-lhes o alvo do coração. Deles só lhes sentia o cheiro do suor e das bostas dos cavalos quando passavam trotando pelo corredor. Por isso não adiantou pôr trancas na porta, nem cobrir-lhes de pregos as tábuas em xis quando eu saía. Muito 
menos valeu o esforço de trocar todas as fechaduras, reforçando-as com cadeados extras. Bem assim como nada valeu em extremar minha vigília e colocar uma cadeira onde eu sentava diante do quarto dela, das seis da tarde às seis da manhã. Tudo era embalde. Eles passavam com seus cavalos alados por cima do telhado, relinchando no alto da noite, atraídos pelo cio da égua que exalava cá do curral (MAIA, 2006, p. 148).

As ações do perpetrador do romance de Maia, bem como a linguagem, apontam para uma mímesis obscena. Termo cunhado por Ligia Maria Winter, a mímesis obscena corresponde ao irrepresentável e ao maldito, que justamente por trair a irrepresentabilidade trás à cena - ao simbólico - a imagem do mal: tudo o que pode desencadear a náusea e que, portanto, deveria estar excluída ou à margem, mas ao contrário, ocupa o centro dela. De acordo com Winter (2008, p.31):

“A expressão mimesis obscena é própria e foi eleita por sua dupla operação: obsceno significa tanto algo indecente, erótico, maldito e imoral (ob-caenum, próximo à sujeira), quanto, homofonicamente e, por sua própria característica marginal, algo que está "fora de cena" (ob-scenus), que foi excluído, recalcado".

$\mathrm{Na}$ condição de narrativa do perpetrador Memórias quase Póstumas de um Ex-torturador parece ser até o momento único no formato romance em língua portuguesa, havendo narrativas semelhantes na contística, conforme aponto no início deste estudo. Contudo, a existência de narrativas como essas agita o modelo da narrativa do perpetrador e abre outras possibilidades literárias para o tratamento de questões relacionadas à violência no interior do estado de exceção.

Por sua vez, Memórias de uma guerra suja é uma narrativa constituída do depoimento do exdelegado Claudio Guerra, ativo participante dos grupos de repressão durante a ditadura civil-militar de 1964, cedido aos jornalistas Marcelo Netto e Rogério Medeiros. Considerando os marcos conceituais e a terminologia propostas por Valeria de Marco (2003) e Cecília Ines Luque (2004) Memórias de uma guerra suja é narrativa em condições de ser pensada como um testemunho mediado ou testemunho romanceado - tal como pensa Valéria de Marco (2004), uma forma de narrativa testemunhal em que se verifica uma autoria assumidamente híbrida, uma vez composta pelo editor responsável por compor - ou reeleborar - um conteúdo testemunhal a partir do depoimento dado a ele por um testemunhante, também autor. Nota-se no testemunho romanceado o cuidado em inserir paratextos (prólogos, anexos, notas e outros dados), que cumprem a função de atestar o que está sendo afirmado e as circunstâncias em que se foi realizada a produção textual, procurando "marcar, -ao menos aparentemente, a separação entre ambos os discursos" (DE MARCO, 2004, p. 47).

Todos esses aspectos estão claramente presentes em Memórias de uma guerra suja: temos o testemunhante - Claudio Guerra - que concede seu depoimento aos jornalistas citados que, na condição de editores, reelaboram e comentam o material cedido. Os paratextos se encontram tanto na abertura do produto, constituídos por "Introdução", "Apresentação" e mais os textos "A trajetória de um matador" e "Resumo de uma luta de 15 anos contra a esquerda", todos de autoria dos dois editores, quanto nos anexos, na forma de um conjunto de notas explicativas de claro cunho jornalístico.

Contudo, Memórias de uma guerra suja, enquanto narrativa, também pode ser lida pela perspectiva da narrativa do perpetrador, uma vez que Claudio Guerra é oficialmente conhecido como um dos maiores matadores da ditadura civil-militar de 1964, tal como afirma Rogério Medeiros (2012, p. 13): "ardiloso e implacável matador, Guerra possuía atributos que levaram o regime militar a recrutá-lo para a cabeceira de seus executores, tornando-o autor de grande parte dos assassinatos dos adversários da ditadura militar".

Assim como Pedro, o protagonista de Memórias quase Póstumas de um Ex-torturador, Claudio Guerra também narra a sua trajetória quando se encontra muito vulnerável: na condição de presidiário condenado, em idade avançada e muito doente em um leito de hospital. No caso de Claudio Guerra 
soma-se ainda o mergulho em uma experiência religiosa que o inclina a fazer uma espécie de acerto de contas com o passado. Assim sendo, não apenas a presença de um personagem que assume a condição de narrador - ou pelo menos de um dos narradores - se configura como característica predominante em narrativas do perpetrador, mas, sobretudo o fato de no presente haver uma condição de vulnerabilidade, que parece ser a responsável imediata pela decisão de narrar do perpetrador.

Saliento também que em ambos os relatos predomina a violência cometida pelo perpetrador, com destaque para as principais funções que ambos os protagonistas desenvolvem na máquina represssora, no interior do regime militar: Pedro, na função de torturador e assassino. E Claudio, ora como assassino, ora como mentor e executor das desaparições. Nesse processo, a cena da tortura é comum nas duas narrativas, embora em Memórias de uma guerra suja seja relatada de maneira breve e seguindo a linha da linguagem jornalística, com um léxico mais formal, e com o protagonista ausente da cena - na condição de um terceiro a narrar - diferenciando-se, portanto, do léxico baseado no baixo calão e carnavalizado, bem como a imersão de um narrador autodiegético, comum às narrativas literárias da mesma vertente. Cito um trecho de Memórias de uma guerra suja que ilustra essa observação:

\begin{abstract}
"Ouvi falar de um cabo que trabalhava lá, o doutor Magno. Ele não só matava e serrava os mortos como punha um ácido para acabar com os corpos. Depois os enterrava, sem chances para a perícia conseguir identificá-los. Era o que se falava no serviço. Sabíamos por razão do ofício. Era um meio de destruir o corpo rapidamente" (GUERRA, NETTO \& MEDEIROS, 2012, p.61).
\end{abstract}

Nesse sentido, a forma do testemunho romanceado de Memórias de uma guerra suja estabelece uma importante diferença em relação a Memórias quase Póstumas de um Ex-torturador: a ausência da linguagem abjeta, mas aqui há uma especificidade formal que justifica essa diferença: apesar da perspectiva ser a do perpetrador a narrativa assume-se desde o início como reescrita de um depoimento, constituída por dois jornalistas. Como é possível observar o trabalho reelaborativo conduz à limpeza do léxico, apresentando, portanto, um vocabulário concernente com a norma padrão e economia nas descrições. Contudo, a ausência da linguagem abjeta não retira de Memórias de uma guerra suja a mimesis obscena observada no romance. A imagem do Mal também aqui se faz presente, na medida em que repercutem em cada atrocidade revelada no testemunho de Claudio Guerra.

O perpetrador é desse modo o ser humano capaz de cometer monstruosidades ou aquele que não se surpreende ou é incapaz de manifestar espanto diante da monstruosidade do outro e sua conduta é um espelho do que representa. Nesse sentido, ambas as narrativas são perturbadoras tanto pelo modo como manuseiam a linguagem, quanto pela figuração monstruosa do protagonista. Nesse percurso, o léxico sanitarizado e a sintaxe organizada, econômica, de Memórias de uma guerra suja é tão perturbadora quanto a linguagem abjeta de Memórias quase Póstumas de um Ex-torturador. A linguagem no relato de Claudio Guerra inquieta porque é incoerente com a realidade evocada, embora coerente com o formato pretendido/assumido no projeto narrativo.

A indiferença dos protagonistas em relação às atrocidades cometidas ou testemunhadas, mesmo imersos em um acerto de contas com seu passado é também uma constante nessas narrativas. Em Memórias quase Póstumas de um Ex-torturador não há qualquer sintoma de arrependimento ou remorso por parte do torturador, apenas a reflexão sobre o caráter especular de uma vida violentada/violenta, em que, ao contrário do que se prenuncia no início da narrativa - a conduta violenta se faz colada à ferida traumática infringida na infância - não há espaço para qualquer laivo de perdão ou de justificativa para a conduta violadora do outro. O perpetrador, ele mesmo e apenas ele, é responsável por sua danação eterna na vida e na morte, que o aguarda com brevidade. Portanto, seu protagonismo se encontra marcado tanto por alguma vulnerabilidade - que traduz esse protagonismo 
em fala - quanto por essa indiferença, não mais que uma máscara da pulsão de morte que sempre o nutriu.

Essa mesma indiferença pode ser identificada em Memórias de uma guerra suja. Mas aqui, ciente de que há certo oportunismo a perdurar em sua fala o narrador trata de justificar (o injustificável) lembrando ao leitor o tempo todo que a engenharia da repressão trabalha baseada também na lógica da sobrevivência e que para sobreviver entre outros perpetradores o perpetrador necessita obedecer a esta lógica para não perecer.

A perspectiva da indiferença não apenas coloca o delito do algoz no epicentro das duas produções, ela investe as narrativas do perpetrador da especulação sobre despotismo e perversão. Essa percepção além de necessária é fundamental. Michel Focault, para quem o déspota é um criminoso por estatuto (FOUCAULT, 2001, p. 117), mostra em seu célebre estudo sobre o monstro humano as aproximações e correspondências entre o déspota e o criminoso em um contexto em que a violência e por extensão o abuso do poder - passa a ser legítima quando sob a ordem do Estado. Desse modo, assim como para Foucault (2001, p. 118) “todos os monstros humanos são descendentes de Luís XVI", todos os perpetradores são filhotes dos déspotas.

\title{
Considerações finais
}

Por último, penso que o protagonismo do perpetrador, com a participação ou mesmo privilégio de sua perspectiva, associada ao fato dessas narrativas serem muito concentradas no espólio da dor e da ferida traumática, resultantes das agressões perpetradas por motivações políticas - qualquer que sejam as motivações políticas - são cruciais para estabelecer uma economia narrativa diferenciada daquelas narrativas também concentradas no espólio da dor e da ferida traumática, mas com perspectiva e/ou protagonismo da vítima. É importante salientar que independente de quem seja o protagonismo o cerne da narrativa é a violência contra o corpo e em seu prosseguimento a amplificação da crítica ao déspota e às formas de despotismo/autoritarismo. Nesse sentido, para uma tentativa de compreensão do lugar dessa forma de narrativa na relação com o romance do ditador, cito mais uma vez Michel Foucault:

\begin{abstract}
"É por um estado de violência permanente que o déspota pode impor sua vontade ao corpo social inteiro. O déspota é, portanto, aquele que exerce em permanência - fora do estatuto e fora da lei, mas de uma maneira que é completamente intricada em sua existência mesma - e que impõe de uma maneira criminosa seu interesse. É o forada-lei permanente, é o indivíduo sem vínculo social. O déspota é o homem só. É aquele que, por sua existência mesma e apenas por sua existência, efetua o crime por excelência, o crime da ruptura total do pacto social pelo qual o próprio corpo da sociedade deve poder existir e manter. (FOUCAULT, 2001a, p. 117)
\end{abstract}

O ditador é um déspota. Um dos principais pontos de aproximação entre formas de governo como despotismo, ditadura e autocracia é a presença do déspota, aquele que exerce o poder sem os limites das leis, sejam elas naturais, consuetudinárias ou imposições de órgãos ad hoc (BOBBIO, 1998, p.340). Considerando esse aspecto e o raciocínio de Foucault sobre as relações entre despotismo e crime, lanço aqui uma resposta ainda provisória sobre assunto: ainda que possa ser compreendido como um rosto - e um tentáculo - do déspota (e que este não seja menos perpetrador) o perpetrador está sob o domínio do déspota.

Embora seu poder sobre a vítima seja absoluto, o perpetrador possui poder limitado no contexto mais amplo da economia despótica. Por esse motivo penso que não há como desintegrar as narrativas com protagonismo do perpetrador do corpus de narrativas do ditador, e nesse sentido ainda que possa ser uma narrativa derivante, é autônoma em relação a esta. 


\section{REFERÊNCIAS}

BATISTA, Suellen Monteiro; SARMENTO-PANTOJA, Tânia. Torturador e torturado: notas sobre ficcionalização do trauma nos contos pós-64. Olho d'água. São José do Rio Preto, v. 6, n. 2, p. 108 119, 2014.

BOBBIO, Norberto, MATTEUCCI, Nicola e PASQUINO, Gianfranco. Dicionário de Política. Tradução de Carmen C, Varriale et AL. Brasília: Universidade de Brasília, 1998.

COURTINE, Jean-Jacques. O corpo anormal - História de antropologia culturais da deformidade. In: CORBIN, Alain; COURTINE, Jean-Jacques; VIGARELLO, Georges (Dir). História do corpo. As mutações do olhar. O século XX. Tradução e revisão Ephraim Ferreira Alves. Petrópolis: Vozes, 2008.

DE MARCO, Valeria. A literatura de testemunho e a violência de Estado. Revista Lua Nova, São Paulo, no 23, 2004.

EMEDIATO, Luiz Fernando. Não Passarás o Jordão. In: EMEDIATO, Luiz Fernando. Verdes anos. 2. ed. São Paulo: Geração Editorial, 1994.

FIUZA, Adriana Aparecida de Figueiredo. Revisitando o passado: trajetórias do romance do ditador na literatura hispano-americana. Graphos. João Pessoa, Vol 10, N. 2, Dez./2008, Vol 11, N. 1, Jun./2009, p. 277-289.

FOCAULT, Michel. . Os anormais: curso no Collège de France (1974-1975). São Paulo: Martins Fontes, 2001

GUERRA, Claudio; NETTO, Marcelo; MEDEIROS, Rogério. Memórias de uma guerra suja. Rio de Janeiro: Topbooks, 2012.

HOBSBAWM, Eric J. Barbárie: Manual do usuário. In: Sobre história. Tradução de Cid Knipel Moreira. São Paulo: Companhia das Letras, 2013.

HUDOIN-ROUZEAU, Stéphane. Massacres - O corpo e a guerra. In: CORBIN, Alain; COURTINE, Jean-Jacques; VIGARELLO, Georges (Dir). História do corpo. As mutações do olhar. O século XX. Tradução e revisão Ephraim Ferreira Alves. Petrópolis: Vozes, 2008.

LUQUE, Cecilia Inês. Balún Canán de Rosários Castellanos: um exemplo de memórias pseudotestimoniales. Coatepec. Toluca: Universidad Autonôma de México, enero-junio, ano/volume II, n.04.

KONDER, Rodolfo. Pedro Ramiro. In: Cadeia para os mortos: histórias de ficção política. São Paulo: 
Alfa- Ômega, 1977.

MAIA, João Bosco. Memórias quase póstumas de um ex-torturador. Belém: IAP, 2006 (prêmio IAP de Literatura)

MARANHÃO, H. O leite em pó da bondade humana. In: MARANHÃO, H. As peles frias. Rio de Janeiro: Francisco Alves, 1983. p. 11-21.

MEDEIROS, Rogério. Introdução. In: GUERRA, Claudio; NETTO, Marcelo; MEDEIROS, Rogério. Memórias de uma guerra suja. Rio de Janeiro: Topbooks, 2012.

MENTON, Seymour. La nueva novela histórica de América Latina: 1979-1992. 1993

SERRÃO, Raquel de Araújo. Ditadura e testemunho: uma realidade na literatura latinoamericana. Olho d'Água, Vol.6, n.1. 2014.

WINTER, Ligia Maria. Mimesis obscena: a imagem da traição na poética da modernidade em um aceno a Fogo pálido, de Vladimir Nabokov. Nonada, Vol. 11, 2008.

Recebido em 20 de novembro de 2018 Aceito em 28de dezembro de 2018 